\title{
Failure of mebendazole to cure trichomonal vaginitis resistant to metronidazole: case reports
}

\author{
R S PATTMAN,* M S SPROTT, $\dagger$ A M KEARNS, $\dagger$ M EARNSHAW $\ddagger$ \\ From the *Department of Genitourinary Medicine; the $\uparrow$ Regional Public Health Laboratory; and the \\ $\ddagger$ Department of Pharmacy, Newcastle General Hospital, Newcastle upon Tyne
}

SUMMARY After a recent report showing the in vitro susceptibility to mebendazole of a strain of Trichomonas vaginalis that was resistant to metronidazole, we present two cases of metronidazole resistant infection, both of which failed to respond to oral mebendazole.

Since 1960 the oral 5-nitroimidazole, metronidazole, which gives cure rates of $86-100 \%$, has been available as the treatment of choice for vaginal trichomoniasis in non-gravid women.' Other nitroimidazoles have been shown to be equally effective. ${ }^{2}$ Since 1978 , however, the emergence of strains of Trichomonas vaginalis that are resistant to metronidazole has been reported. ${ }^{3-7}$ This resistance appears to be associated with greatly decreased susceptibility to the other available 5-nitroimidazoles, tinidazole and nimorazole. ${ }^{8}$ Alternative treatment is obviously necessary.

In January 1988 Sears and O'Hare reported on the in vitro activity of 50 different antimicrobial agents against five strains of $T$ vaginalis. ${ }^{9}$ Four were susceptible to metronidazole, but the fifth was resistant. Against this metronidazole resistant strain three agents, anisomycin, furazolidone, and mebendazole were reported as being active. Only the latter is available in this country. As two women attending this department of genitourinary medicine were infected with $T$ vaginalis that was established as being resistant to metronidazole, we decided, with their informed consent, to assess the efficacy of mebendazole.

\section{Case reports}

CASE 1

A single woman (a nurse) aged 22 attended in December 1987 with trichomonal vaginitis. She had apparently acquired her infection in September 1987 while in Israel, and had already been given metronidazole but had not experienced symptomatic improvement. She was treated initially with a combination of metronidazole $(400 \mathrm{mg}$ twice a day for seven

Address for reprints: Dr R S Pattman, Ward 34, Department of Genitourinary Medicine, Newcastle General Hospital, Westgate Road, Newcastle upon Tyne NE4 6BE

Accepted for publication 11 May 1989 days) and ampicillin ( $250 \mathrm{mg}$ four times a day for five days), both by mouth. The ampicillin was prescribed to cover the possibility of associated metronidazole inactivating organisms. Subsequent endocervical cultures gave negative results for Neisseria gonorrhoeae but positive for Chlamydia trachomatis. Triple tetracycline was therefore prescribed in a dose of $300 \mathrm{mg}$ twice a day for two weeks. As the trichomoniasis persisted, she was given concurrent nimorazole $1 \mathrm{~g}$ every 12 hours for three days.

On further review she remained heavily infected with $T$ vaginalis. She had not had sexual intercourse. Her serum zinc concentration was $10 \cdot 1 \mu \mathrm{mol} / 1$ (normal range 9.5-17 $\mu \mathrm{mol} / \mathrm{l})$. The minimum inhibitory concentration (MIC) of metronidazole against the organism under aerobic conditions was $125 \mathrm{mg} / \mathrm{l}$ (control strain $1 \mathrm{mg} / \mathrm{l}$ ), and the MIC of nimorazole was $4 \mathrm{mg} / \mathrm{l}$ (control strain $2 \mathrm{mg} / \mathrm{l}$ ). Oral mebendazole was prescribed in a dosage of $100 \mathrm{mg}$ twice a day for three days, and the patient was also asked to insert two $100 \mathrm{mg}$ mebendazole tablets into her vagina at night. She returned after a week with continuing trichomoniasis, and stated that the mebendazole had failed to dissolve in her vagina. She was then given oral mebendazole only, $400 \mathrm{mg}$ three times a day for one week, to be taken with fatty food. Again she failed to respond clinically or microbiologically, but tolerated the treatment apart from slight gastrointestinal hurry.

CASE 2

A married housewife aged 50 was referred by her general practitioner in January 1988 with a four year history of recurrent trichomoniasis, which had failed to respond to numerous courses of metronidazole. She had refrained from sexual intercourse during this time and claimed that her husband had already received epidemiological treatment with metronidazole. Hysterectomy had been performed two years previously for menorrhagia.

Trichomonal vaginitis was confirmed microscopi- 
cally, and she was treated initially with a combination of oral metronidazole $(400 \mathrm{mg}$ twice a day for seven days) and ampicillin ( $250 \mathrm{mg}$ four times a day for five days). Endocervical cultures for $N$ gonorrhoeae and $C$ trachomatis repeatedly gave negative results, and her serum zinc concentration was $11.3 \mu \mathrm{mol} / \mathrm{l}$ (normal range 9.5-17 $\mu \mathrm{mol} / \mathrm{l})$. The MIC of metronidazole against the $T$ vaginalis strain isolated on culture was 32 $\mathrm{mg} / \mathrm{l}$ under aerobic conditions.

At review her condition was unchanged, and she was given oral nimorazole ( $1 \mathrm{~g}$ every 12 hours for 36 hours) in combination with povidone-iodine pessaries (200 mg inserted at night for seven days). No improvement was seen clinically or microbiologically so we prescribed oral mebendazole, initially in a dose of $400 \mathrm{mg}$ twice a day for seven days and then $\mathbf{4 0 0} \mathrm{mg}$ three times a day for seven days, advising the patient to take the tablets with fatty foods. At follow up, her symptoms were unaltered, and numerous trichomonads were found in the vaginal fluid. She reported no side effects.

\section{Discussion}

Metronidazole resistant strains of $T$ vaginalis were identified in both patients after they had received repeated previous treatment with this agent. Forsgren and Forssman have suggested that suboptimal doses of metronidazole in vaginal secretions may induce imidazole resistance. ${ }^{4}$ Low plasma zinc concentrations have been reported as being related to recalcitrant vaginal trichomoniasis, and a therapeutic response to metronidazole occurred only when plasma zinc concentrations returned to normal after a three week course of oral zinc sulphate. ${ }^{10}$ In both our patients serum zinc concentrations were within the normal range. Treatment failure related to the presence of organisms that inactivate metronidazole has been reported by several authors. ${ }^{11}{ }^{12}$ In view of this, our current policy for patients with recalcitrant trichomoniasis is to submit samples of vaginal secretions for bacteriological culture and to prescribe a combination of metronidazole and ampicillin. Additional vaginal swabs taken from one patient (case 1) showed two types of diphtheroids and a metronidazole resistant penicillin sensitive streptococcus that failed to grow, even on prolonged culture, in other than anaerobic atmospheres. The other patient (case 2) yielded diphtheroids, Streptococcus faecalis, coagulase negative staphylococci, and metronidazole resistant penicillin sensitive Bacteroides melaninogenicus. ${ }^{13}$ Although the potentially inactivating organisms showed sensitivity to ampicillin, the patients failed to respond to routine combination treatment with ampicillin and metronidazole.

Alternative treatment with 5-nitroimidazoles proved to be unsuccessful. These agents are apparently absorbed passively by $T$ vaginalis. Their nitro group is thought to be reduced by hydrogenosomes in the cytoplasm under anaerobic conditions to form cytotoxic nitro radical anions. ${ }^{14}$

Sears and O'Hare observed that a metronidazole resistant laboratory strain of $T$ vaginalis (aerobic MIC $100 \mathrm{mg} / \mathrm{l})$ was much more susceptible in vitro to mebendazole (aerobic MIC $3.1 \mathrm{mg} / \mathrm{l}){ }^{9}$ Mebendazole is a microtubular inhibitor indicated for treating patients with helminthic infections. It is poorly absorbed from the gastrointestinal tract and is almost insoluble in water and dilute mineral acids. Münst, Karlagamis, and Bircher have shown that when $1.5 \mathrm{~g}$ mebendazole was administered to three fasting patients their plasma concentrations did not exceed 17 nmol/l, but when mebendazole was given with food peak plasma concentrations reached 91 to $142 \mathrm{nmol} / 1$ within two to four hours. ${ }^{15}$ They advised giving mebendazole with food, as we recommended to our patients. Our limited experience showed that using the oral mebendazole tablet as a vaginal pessary was unsuccessful because it failed to dissolve. Although one patient experienced slight gastrointestinal hurry, there were no serious side effects. Unfortunately, however, neither of our patients experienced any therapeutic effect.

\section{References}

1 Lumsden WHR, Robertson DHH, Heyworth R, Harrison C. Treatment failure in Trichomonal vaginalis vaginitis. Genitourin Med 1988;64:217-8.

2 Meingassner JG, Heyworth PG. Intestinal and urogenital flagellates. Antibiot Chemother 1981;30:163-202.

3 Thurner J, Meingassner JG. Isolation of Trichomonas vaginalis resistant to metronidazole. Lancet 1978;ii:738.

4 Forsgren A, Forssman L. Metronidazole-resistant Trichomonas vaginalis. British Journal of Venereal Diseases 1979;55:351-3.

5 Kulda J, Vojtěchovská M, Tachezy J, Demés P, Kunzová E. Metronidazole resistance of Trichomonas vaginalis as a cause of treatment failure in trichomoniasis: case report. British Journal of Venereal Diseases 1982;58:394-9.

6 Müller M, Meingassner JG, Miller WA, Ledger WJ. Three metronidazole resistant strains of Trichomonas vaginalis from the United States. Am J Obstet Gynecol 1980;138:808-12.

7 Goulton J, Squires S. Metronidazole-resistant Trichomonas vaginalis. Lancet 1982;i:42.

8 Meingassner JG, Thurner J. Strain of Trichomonas vaginalis resistant to metronidazole and other 5-nitroimidazoles. Antimicrob Agents Chemother 1979;15:254-7.

9 Sears SD, O'Hare J. In vitro susceptibility of Trichomonas vaginalis to 50 antimicrobial agents. Antimicrob Agents Chemother 1988;32:144-6.

10 Willmott F, Say J, Downey D, Hookham A. Zinc and recalcitrant trichomoniasis. Lancet 1983; i:1053.

11 Edwards DI, Thompson EJ, Tomusange J. Inactivation of metronidazole by aerobic organisms. J Antimicrob Chemother 1979;5:315-6.

12 Ralph ED, Clarke DA. Inactivation of metronidazole by anaerobic and aerobic bacteria. Antimicrob Agents Chemother 1978;14:377-83.

13 Sprott MS, Kearns AM. Metronidazole-resistant Bacteroides melaninogenicus. J Antimicrob Chemother 1988;22:951-2.

14 Lindmark DG, Müller M. Antitrichomonad action, mutagenicity, and reduction of metronidazole and other nitroimidazoles. Antimicrob Agents Chemother 1976;10:476-82.

15 Münst GJ, Karlagamis G, Birchen J. Plasma concentrations of mebendazole during treatment of echinococcosis. Eur $J$ Clin Pharmacol 1980;17:375-8. 